\title{
School Crime and Disruption as a Function of Student-School Fit: An Empirical Assessment
}

\author{
Richard A. Kulka, ${ }^{1}$ David M. Klingel, ${ }^{2}$ and David W. Mann ${ }^{3}$
}

Receiled February 4, 1980

A theoretical model is described which conceptualizes school crime and disruption as a function of the congruence or fit between the personal characteristics of students and the social environments of the schools they attend. In a direct empirical test of the model, indices representing 10 distinct dimensions of student-school fit are related to three composite measures of school misconduct: school crime, school avoidance, and class misbehavior. A number of significant relationships are found between dimensions of student-school fit and the three indices of school misbehavior, several of which manifest one of the nonlinear forms specified by the model, providing at least modest support for a person-environment fit theory of school crime and disruption.

An earlier version of this paper was presented at the annual meeting of the Society for the Study of Social Problems, San Francisco, September 1978. Analyses reported here were supported by a research grant (G-78-0049) from the National Institute of Education.

'Study Director, Survey Research Center, Institute for Social Research, University of Michigan, Received Ph.D. in social psychology from the University of Michigan. Current research interests include alienation and involvement in high school, person-environment fit, and survey methodology.

${ }^{2}$ Research Associate, Survey Research Center, Institute for Social Research, University of Michigan, Current research interests include the development and treatment of aggressive and deviant behavior in adolescence and socialization experiences in high school.

${ }^{3}$ Study Director, Research Center for Group Dynamics, Institute for Social Research, University of Michigan. Received Ph.D. in personality psychology from the University of Michigan. Current research interests include adolescent self-esteem, delinquent behavior, and alternative schools. 


\section{INTRODUCTION}

Although various forms of student misconduct have long been a notable feature of the American educational scene, in recent years public attention has been focused on evidence of more serious problems - those of violence, vandalism, crime, and disruption in our nation's schools. Parents, teachers, administrators, and the mass media have all expressed serious concern about the problem, and exhaustive hearings held in the early 1970s by the U.S. Senate Subcommittee to Investigate Juvenile Delinquency (1977) documented mounting evidence of school violence and vandalism. While a variety of sources have indicated that acts of violence and vandalism in our schools increased from the early 1960 s to the early 1970 s and leveled off thereafter, systematic data recently made available from the HEW Safe School Study emphasize that "the problem today is as serious as it has ever been" and "there is abundant evidence of a problem requiring concerted action" (National Institute of Education, 1977, pp. 2, 12).

Because this marked escalation of public concern over school violence, vandalism, and crime has occurred primarily over the past 5 or 10 years, few rigorous studies exist which focus specifically on the nature and causes of criminal behavior in the school context, and those available are of quite recent vintage (Bailey, 1970; Cardinell, 1969; Goldman, 1961; Greenberg, 1975; McPartland and McDill, 1977; National Institute of Education, 1977). While the paucity of systematic research on school crime is indeed unfortunate from the viewpoint of education practitioners, it presents a rare opportunity in the annals of social science research: the opportunity to develop an adequate and systematic conceptualization of the problem prior to extensive research or broad scale intervention. Because "conceptual frameworks largely determine what we look for and what we find" (e.g., Strauss, 1974), the selection of an appropriate conceptual model may be considered the fundamental task in our efforts to understand and deal with school crime.

Accordingly, in a recent paper on the subject (Kulka et al., in press), we emphasized the need for a conceptual model of school crime of sufficient scope to account for delinquent behavior in general, as well as for delinquency and disruption within the school setting (cf. Wilson, 1977). The type of theory required, in our view, is a multilevel interactive behavioral model (Yinger, 1965) of school crime, which characterizes delinquent behavior as a function of the interaction of personal characteristics of adolescents and characteristics of their social environments or the situations youth confront. Impressed by the fact that models of person-environment congruence or fit have been effectively used to specify the nature of this interaction in virtually every major area of social research other than crime and delinquency (for an extensive review and critique of theory and research on person-environment fit, see Kulka, 
1975,1979 ), we proposed a model based on a quantitative schema proposed by French et al. (1974), which conceptualizes school crime and disruption as a function of the congruence or fit between personal characteristics of students and the social environments of the schools they attend.

Because direct empirical support for the model was largely unavailable, we relied primarily on two types of indirect evidence to demonstrate the potential utility of the theory. First, we sought to illustrate the considerable conceptual overlap between the model and several traditional theories of delinquent behavior. Second, we attempted to show that certain research findings in the delinquency literature may reasonably be interpreted in terms of the model. In this paper, we will present more direct empirical evidence relevant to our person-environment congruence model of school crime by relating several explicit measures of person-environment fit to three composite measures of school misconduct. Before doing so, we will briefly describe the general model of person-environment (P-E) fit.

\section{A MODEL OF PERSON-ENVIRONMENT FIT}

The basic assumption of the model, which has now been elaborated in a number of papers (Caplan et al., 1975; French, 1973; French et al., 1974; Harrison, 1978; Kulka, 1975, 1979), is that adjustment may be conceived of as the goodness-of-fit between characteristics of the person and properties of his or her environment. As one concept of adjustment or stress, personenvironment fit may be viewed as an important predictor of psychological strain and other indicators of mental health, including various adaptive or maladaptive behaviors produced in response to strain.

The theory may be described in terms of a few basic concepts. First, the model proposes four basic elements: (a) the objective environment, which includes aspects of the physical and social world that exist independently of the person's perceptions of them; (b) the subjective environment, which represents the person's perceptions and cognitions of relevant aspects of his or her objective environment; (c) the objective person, the objectively demonstrable characteristics of the person (i.e., needs, values, abilities, and other relatively enduring attributes), independent of his or her perceptions; and (d) the subjective person, the individual's perceptions or cognitions of his or her objective characteristics (i.e., self-concept or self-identity). Employing these four elements, the model distinguishes between subjective person-environment fit, where both characteristics of the person and the environment are assessed as perceived and reported by the person, and objective person-environment fit, where both components are measured independent of the person's perceptions and cognitions of them. 


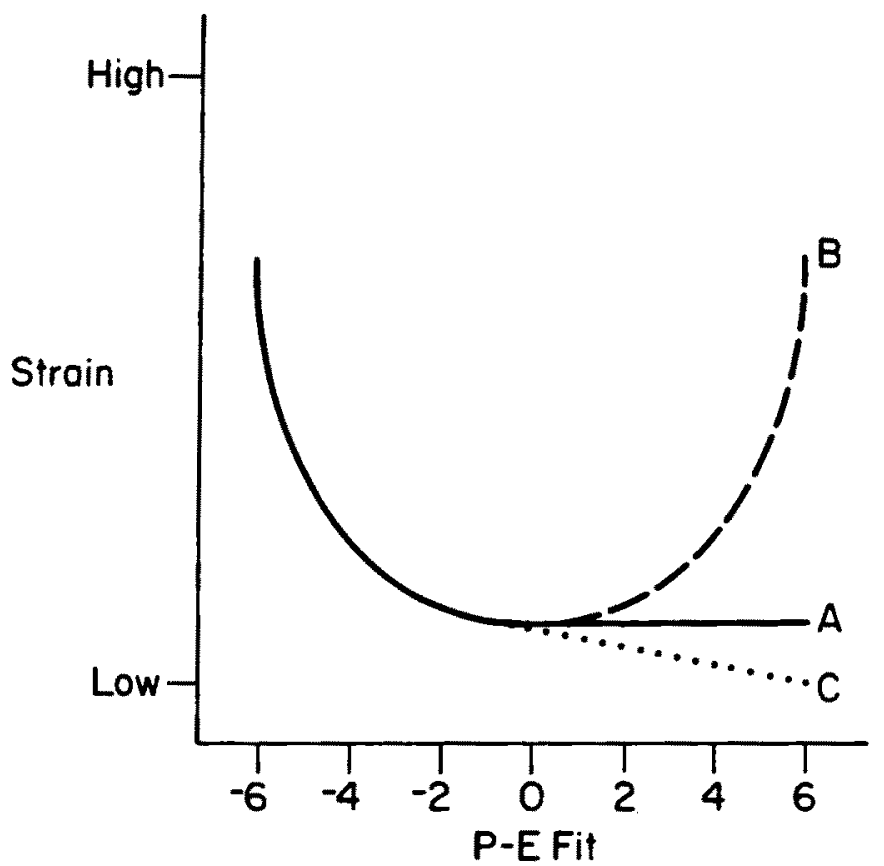

Fig. 1. Three hypothetical person-environment fit curves. The hypothesized relationship between P-E fit and psychological strain, as adapted from French et al. (1974).

Second, the theory proposes that for both objective and subjective P-E fit there are two basic subtypes, describable in terms of two sorts of demands and two corresponding forms of supplies to meet these demands. The motives (needs or values) of the person represent one type of demand which may or may not be met by environmental supplies in the form of opportunities for gratification. The other form of demand emanates from the environment in terms of role demands or requirements, where the supplies to meet such demands consist of the skills or abilities of the person. Thus, strain may result from misfit either (a) between environmental demands and an individual's abilities to meet them, or (b) between an individual's needs or values and environmental resources to gratify these motives - with either form of misfit being conceived of as a manifestation of social stress.

Third, corresponding demands and supplies in each pair are to be conceptualized along commensurate dimensions and measured using the same units of measurement (after Lewin, 1951). Thus conceptualized and measured, person-environment fit may be precisely quantified as the algebraic discrepancy or difference between corresponding demands and supplies. Although 


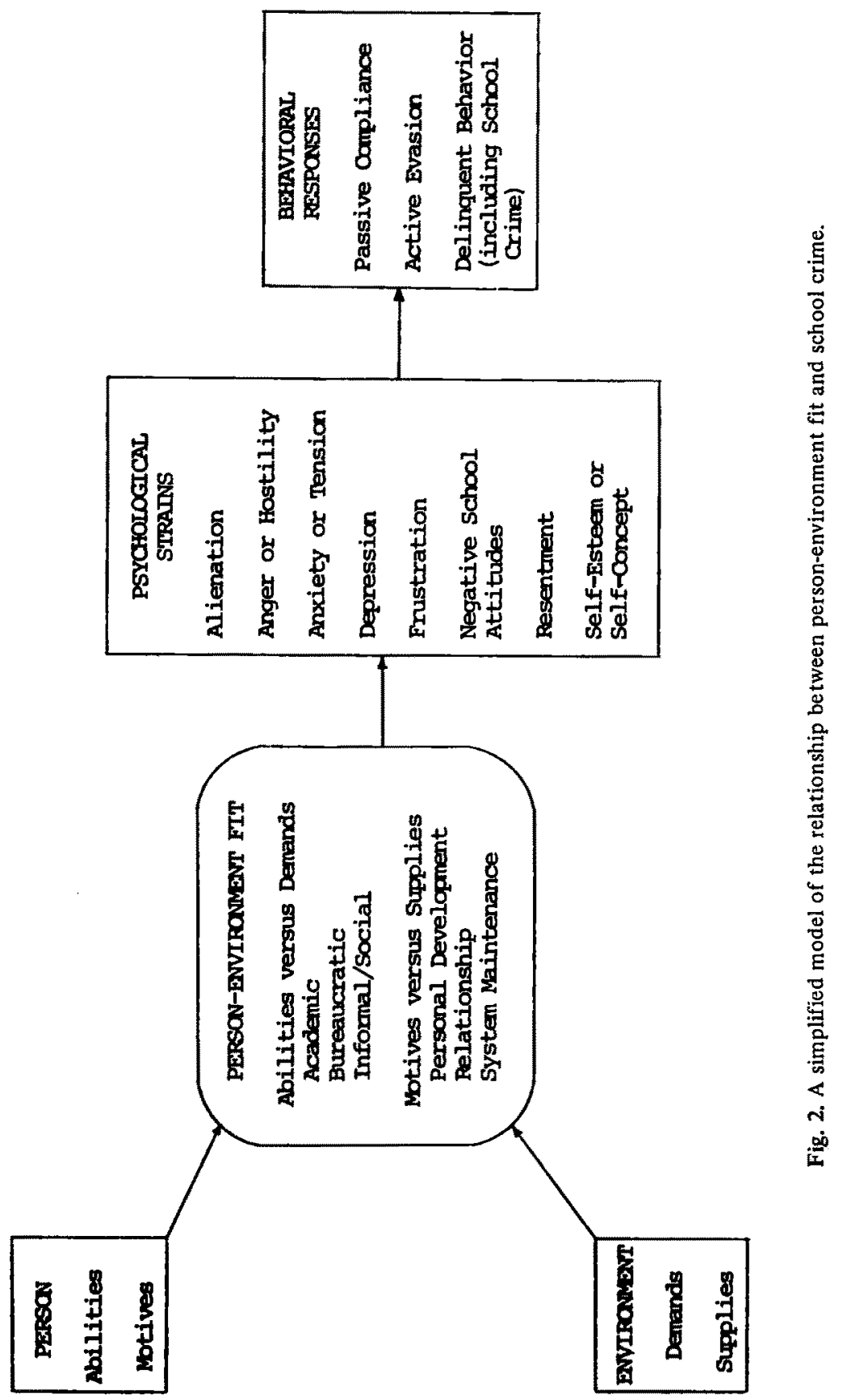


not critical to the model, measures of fit are generally constructed so that positive values indicate excessive supplies, while negative values indicate deficiencies.

Hypothesized relationships between various dimensions of person-environment fit and strains are generally represented by one of three hypothetical functions, as illustrated in Figure 1. Curve A illustrates a monotonic curvilinear relationship between size of deficiency for a particular resource or ability and a given measure of strain, with excess of either environmental or personal supplies having no influence on the level of strain. Thus, the curve of strain plotted against person-environment fit decreases as the magnitude of deficiency decreases, reaching an asymptote at perfect fit and showing no further changes with increasing excesses of supplies. For example, a thirsty man will drink until he has quenched his thirst, after which additional supplies of water will not result in greater satisfaction.

In contrast, the other two curves reflect hypotheses which suggest that excess supplies or abilities will make a difference. In one instance (Curve B) the relationship between fit and strain is U-shaped, strain being lowest at the point of perfect fit, but rising with increases in either deficiency or excess. This type of relationship is proposed where two or more important motives are involved and the presence of excess supplies for one motive may result in deficient supplies for another. For example, if academic abilities are exceeded by teacher demands, strain would result, as in Curve A. However, as abilities increasingly exceed demands, boredom, apathy, or resentment may result as a consequence of the frustration of lack of opportunity to use a valued skill.

A similar example may be used to illustrate the hypothesis suggested by Curve $C$, whereby excess supplies may result in decreased levels of strain. Such relationships are posited when excess supplies for one motive can be used directly as (or exchanged for) supplies for other motives. Accordingly, students whose reading abilities exceed the level of difficulty of materials used for reading instruction may show fewer behavioral symptoms of strain than those whose ability matches the material because a variety of other rewards (e.g., teacher praise, grades) may be associated with that relationship (Jorgenson, 1977). Empirical relationships approximating each of these three hypothetical functions have been reported in recent studies by Harrison (1978), Kulka (1975), and Caplan et al. (1975).

Although a general model of person-environment fit applied to the problem of delinquent behavior or school crime ideally should include a description of the broad range of institutions confronted by children and adolescents, we have chosen in our recent work to focus on the school experience, primarily in deference to the large body of empirical research which suggests the critical importance of school experiences, involvements, and performance in the prediction of disruptive, rebellious, and delinquent behavior (e.g., Elliott and Voss, 
1974; Erickson et al., 1964; Glaser, 1975; Gold, 1978; Hirschi, 1977; Kulka et al., 1979; Polk and Schafer, 1972; Wenk, 1974; West, 1975). In Figure 2 we present a more specific model of the theoretical relationship between school crime and person-environment fit, proposing a conceptualization of schoolrelated delinquency (as a subset of delinquent behavior in general) which treats the problem as a behavioral response to various forms of psychological strain engendered by the school experience. On the one hand are the strains of selfdenigration and anxiety resulting from failure to meet school-related role demands. On the other are the strains of dissatisfaction and alienation resulting from the persistent frustration of the salient needs or values of students.

\section{METHOD}

\section{The Sample}

The results to be presented are based on survey data collected by selfadministered questionnaries from a random cross-sectional sample of 997 male and 1023 female students in grades 10-12 at two Detroit suburban high schools in spring 1973, as part of a larger (longitudinal) study of "Adaptive Behavior in Varied High School Environments," conducted by the Institute for Social Research at The University of Michigan (cf. Kahle et al., in press; Kelly, 1979; Locksley and Douvan, 1979; Newman, 1975). The total number of acceptable questionnaires obtained (2020) represented an overall response rate of $83.9 \%$ of the sample, with little variation in response rate by either sex or school. For the analyses presented here data for the two schools are combined, since preliminary analyses revealed few between school differences in the relationships to be examined.

\section{MEASURES}

\section{Dimensions of Student-School Fit}

Given our basic distinction between two major categories of personenvironment fit, the selection of salient dimensions within each type required that we ask, what major tasks, dilemmas, or problems confront adolescents in the social environment of the school? In this study, we explicitly attempted to conceptualize and measure the most critical dimensions of subjective personenvironment fit in the high school by developing commensurate measures of person and environment for both the ability-demand and need-opportunity dimensions suggested by the model. For each item, respondents were asked 
to indicate the degree of supply or demand on a 7-point scale. To obtain measures of P-E fit, algebraic difference scores were created for each commensurate pair of items by subtracting the score on one item from the score on the other, either ability minus demand (A-D) or opportunity minus need (O-N).

Based on these discrepancy variables, 10 indices of person-environment fit were derived by cluster/factor analyses and labeled according to their content (see Table I). Reliability estimates for the 10 indices, both by sex and for the total sample, are provided in Table II. Four ability-demand indices (Part I of Table I) were called (a) Affiliative, (b) Student Role, (c) Extended Student Role, and (d) Social Leadership. Affiliative $A-D$ assesses fit with respect to friendship or social skills and expectations of parents, peers, and the school for such behavior. Student Role $A-D$ measures fit with regard to both academic and institutional requirements of the conventional role of student (e.g., effort, achievement, attention), while Extended Student Role $A-D$ assesses congruence in less conventional or less mandatory aspects of the student role (e.g., selfutilization, creativity). Social Leadership $A-D$ measures the extent of fit between abilities and requirements from school, friends, and parents for extracurricular and athletic participation.

Six opportunity-need (O-N) indices (Part II of Table I) were designated: (a) School Relevance, (b) Achievement, (c) Social Status, (d) Affiliation, (e) Teacher Support, and (f) Student Influence. School Relevance $O-N$ measures the degree of fit between student needs and provisions by the school for a clear relationship between the tasks of schooling and one's future goals. Achievement $O-N$ primarily assesses the congruence between motives and supplies for achievement (challenge, competition, accomplishment), self-development, and recognition; while Social Status $O-N$ measures fit with respect to peer or social status (cf. Coleman, 1961). Affiliation $O-N$ measures the fit between student desires and opportunities for achieving close interpersonal relationships and friendships with peers in school. Teacher Support $O-N$ measures the degree of need-opportunity congruence with respect to teacher control and supportiveness, such as encouragement, interest, confidence, trust, guidance, and clarity. Student Influence $O-N$ assesses the degree of fit between student needs and chances provided by the school for autonomy, control, and participation in school decision making.

A number of analyses conducted using these measures indicate that both ability-demand and opportunity-need dimensions of fit are significantly related to a wide variety of school adjustment indices for both males and females, including measures of affective states, self-concept/social competence, attitudes toward school, and rebellious behavior (Kulka, 1975). Moreover, many of these relationships between dimensions of P-E fit and criteria of adjustment manifest one of the nonlinear forms illustrated in Figure 1. 
Table 1. Component Items of 10 Indices of Student-School Fit and 3 Indices of School Misbehavior

I. Ability-Demand Indices (A-D)

A. Affiliative A-D

1. Making close friends at school (Capable of/School Expect)

2. Having dates (Capable of/Friends Expect)

3. Having dates (Capable of/Parents Expect)

4. Get along well with girls your age (Able to/Friends Expect)

5. Get along well with boys your age (Able to/Friends Expect)

6. Be popular and well liked at school (Able to/Parents Expect)

B. Student Role A-D

1. Acting like and adult in school (Capable of/Teachers Expect)

2. Get good grades (Capable of/Parents Expect)

3. Stay alert and pay attention in class (Able to/Teachers Expect)

4. How much effort put into schoolwork (Capable of/Teachers Expect)

5. How much effort put into schoolwork (Capable of/Parents Expect)

6. How much speak up in class when there is a discussion (Capable of/Teachers Expect)

C. Extended Student Role A-D

1. Being creative and imaginative in school (Capable of/School Expect)

2. Use your skills, talents, and abilities to fullest (Can/School Expect)

3. Get along well with adults (Able to/School Expect)

D. Social Leadership A-D

1. Being a good athlete (Capable of/School Expect)

2. Being a leader in school (Capable of/Friends Expect)

3. Being involved in athletics (Capable of/Friends Expect)

4. Being involved in athletics (Capable of/Parents Expect)

5. Being involved in other extra-curricular activities (Capable of/Friends Expect)

6. Being involved in other extra-curricular activities (Capable of/Parents Expect)

II. Opportunity-Need indices ( $-\mathrm{N}$ )

A. School Relevance O-N

1. Time to do things that have real value for your future (How Much: School Give/You Want)

2. Your high school courses help you to get the kind of job you want (How Much: Will/You Want)

3. Improve your ability to think and solve problems (How Much: Does School/ Do You Want)

B. Achievement $\mathrm{O}-\mathrm{N}$

1. To do well academically (How Much: Chance School Give/Would You Like)

2. To do things that are challenging (How Much: Chance School Give/Would You Like)

3. To improve yourself in school (How Much: Chance School Give/Would You Like)

4. To win in competition with other students (How Much: Chance School Give/ Would You Like)

5. To be creative and imaginative (How Much: Chance School Give/Would You Like)

6. To feel that you have done a good job at something (How Much: Chance School Give/Would You Like)

7. Recognition school gives you for good academic work (How Much: Does School Give/Would You Like)

C. Social Status $\mathrm{O}-\mathrm{N}$

1. To what extent ... part of the leading crowd here at school (Are You/Would You Like To Be)

2. Close to the center of things in school (How Close Are You/Would Like To Be) 
Table I. Continued

D. Affiliation $\mathrm{O}-\mathrm{N}$

1. Be with your friends and enjoy their company in school (How Much Chance: School Give/Would You Like)

2. To make good friends that you can get together and do interesting things with (How Much: Opportunity School Provide/Would You Like)

3. Free time during a regular school day to be with your friends (How Much: You Have/Would Like)

4. To get to know girls (To What Extent: School Give Chance/Would You Like)

5. To get to know boys (To What Extent: School Give Chance/Would You Like)

6. To make close friends that you can trust and confide in (To What Extent: School Provide Opportunity/Would You Like)

E. Teacher Support O-N

1. To choose assignments of topics for schoolwork (How Much Opportunity: Do You Have/Would You Like)

2. Personal interest teachers take in you (How Much: Do/Would You Like)

3. Teachers and counselors treat you as an adult (To What Extent: Do/Would You Like)

4. Teachers make group assignments or allow students to do their work in groups (To What Extent: Do/Would You Like)

5. Teachers have confidence in you and trust you (To What Extent: Do/Would You Like)

6. Your courses and assignments clearly defined for you (To What Extent: Are/ Would You Like)

7. Your teachers willing to listen to your problems (To What Extent: Are/Would You Like... To Be)

8. Teachers at school friendly and easy to approach (To What Extent: Are/ Would You Like ... To Be)

F. Student Influence $\mathrm{O}-\mathrm{N}$

1. How much say ... in making and carrying out school conduct rules (Do You Have/Would You Like)

2. How much say ... in how this school is run (Do You Have/Would You Like)

3. How much control ... over what happens to you at school (Do You Have/ Would You Like)

4. How much influence ... over student clubs and social events at your school (Do You Have/Would You Like)

5. How much variety... your academic program give you (Does/Would You Like)

6. How much ... clubs or activites at school reflect your personal interests and abilities (Do/Would You Like)

7. To what extent ... your school provide elbow room, to let you feel uncrowded and not hemmed in (Does/Would You Like)

8. To what extent ... your school allow students to create new activities and groups (Does/Would You Like)

III. School Misbehavior Indices

A. School Crime

1. Intentionally damage school property

2. Physically fight with another student

3. Take something that did not belong to you

4. Seriously tell off or threaten another student

5. Punch or push around another student 
Table I. Continued

B. School Avoidance

1. Bring something to school that is against the rules, such as drugs, alcohol, or a weapon

2. Skip a class

3. Skip a day of school without a valid excuse

4. Been suspended or expelled from this school

C. Class Misbehavior

1. Argue with a teacher

2. Refuse to listen to or talk with a teacher

3. Wise off and disrupt a class

4. Being sent out of class by a teacher you didn't get along with

\section{Measures of School Crime and Disruption}

Of particular interest here are potential relationships between the 10 dimensions of fit and indicators of school crime or disruption. From a larger pool of items designed to assess various forms of school misconduct, we selected behaviors that appeared serious enough to be classified as "school crime

Table II. Internal Consistency of Composite Measures

\begin{tabular}{|c|c|c|c|c|}
\hline & \multirow[b]{2}{*}{ Composite measures } & \multicolumn{3}{|c|}{ Spearman-Brown $r_{\mathrm{W}}$ for: } \\
\hline & & Males & Females & $\begin{array}{c}\text { Total } \\
\text { sample }\end{array}$ \\
\hline \multirow[t]{5}{*}{ A. } & Ability-Demand & & & \\
\hline & Affiliative A-D & 0.76 & 0.78 & 0.77 \\
\hline & Student Role A-D & 0.75 & 0.74 & 0.74 \\
\hline & Extended Student Role A-D & 0.53 & 0.54 & 0.54 \\
\hline & Social Leadership A-D & 0.79 & 0.79 & 0.79 \\
\hline \multirow[t]{7}{*}{ B. } & Opportunity-Need & & & \\
\hline & School Relevance O-N & 0.65 & 0.66 & 0.66 \\
\hline & Achievement O-N & 0.77 & 0.80 & 0.79 \\
\hline & Social Status $\mathrm{O}-\mathrm{N}$ & 0.51 & 0.57 & 0.55 \\
\hline & Affiliation O-N & 0.74 & 0.81 & 0.79 \\
\hline & Teacher Support O-N & 0.79 & 0.79 & 0.79 \\
\hline & Student Influence $\mathrm{O}-\mathrm{N}$ & 0.71 & 0.75 & 0.73 \\
\hline \multirow[t]{4}{*}{ C. } & School Misbehavior & & & \\
\hline & School Crime & 0.88 & 0.62 & 0.86 \\
\hline & School Avoidance & 0.64 & 0.57 & 0.63 \\
\hline & Class Misbehavior & 0.76 & 0.69 & 0.77 \\
\hline
\end{tabular}




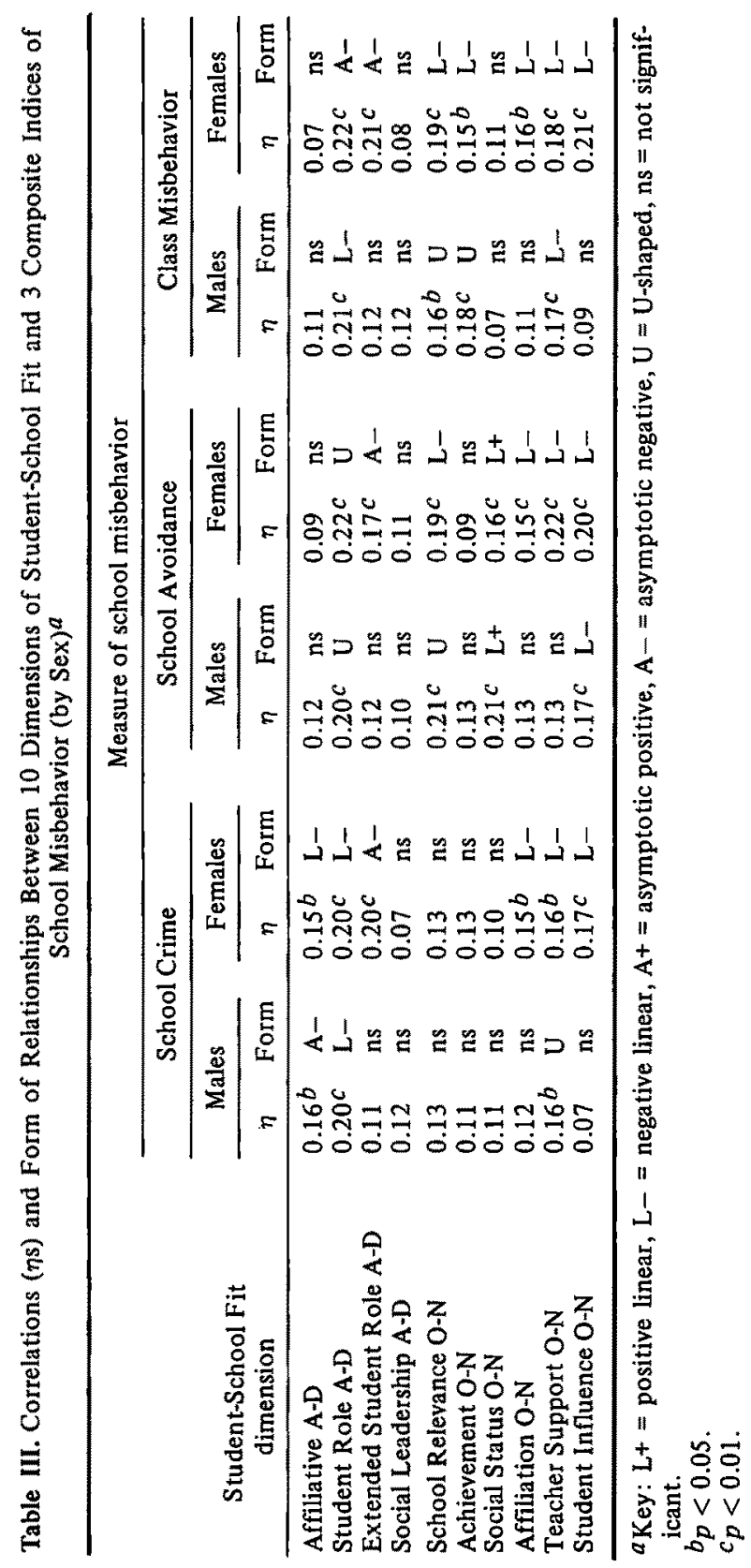


or disruption." A factor analysis of these measures resulted in three distinct clusters of items, which were subsequently combined to form 3 composite indices of school misbehavior: (a) an explicit index of School Crime (based on self-reports of vandalism, theft, and fighting with or threatening another student); (b) a measure of School Avoidance; and (c) a measure of Class Misbehavior. Component items and reliability estimates for these three indices are presented in Part III of Table I and Part C of Table II, respectively. Although responses to the items were in terms of frequency of occurrence over a specified period, the indices are derived as the percentiled sums of standardized item scores.

\section{RESULTS}

Relationships between the 10 dimensions of person-environment fit and the 3 measures of school misconduct are presented in Table III, separately for males and females. Because the model predicts curvilinear relationships between fit and strain, eta $(\eta)$ rather than the product-moment correlation coefficient $(r)$ was selected as the appropriate measure of association. Overall, half the possible relationships between the P-E fit indices and measures of school misbehavior are statistically significant, one-third of the relationships for boys and two-thirds for girls. Person-environment fit between abilities and demands in the student role is significantly related to all 3 measures for both sexes, as is the teacher support measure, with one exception. For females only, discrepancies between abilities and demands in the extended student role and opportunities and needs with respect to affiliation are also significantly associated with all three measures of school misbehavior. Other significant relationships apparent for both males and females are: (a) congruence between affiliative abilities and demands with school crime; (b) discrepancies between opportunities and needs for relevance, social status, and influence with school avoidance, and (c) opportunity-need fit for relevance and achievement with class misbehavior. In contrast, only the social leadership dimension shows no significant association with any of the misconduct indices for either sex.

In addition, a series of tests for the presence of nonlinearity (cf. Blalock, 1960; pp. 314-317), also summarized in Table III, revealed that, while most of these significant relationships may be characterized as essentially linear, over half of the significant relationships for boys and one-fourth of those for girls approximate one of the nonlinear forms predicted by the model (e.g., either U-shaped or asymptotic). Although linear relationships are, strictly speaking, not predicted by the model, it is important to note that the empirical distinction between a "linear" and an "exponential" function (such as that 
represented by Curve $C$ in Figure 1) is largely one of degree. Note also that, while 4 out of 5 nonlinear relationships for girls are asymptotic, 5 out of 6 curvilinear relationships for boys are roughly U-shaped. This general pattern of a greater number of significant relationships for females, in conjunction with a higher proportion of nonlinear and U-shaped relationships for males, replicates a trend discovered earlier for a broader range of school adjustment indicators (Kulka, 1975).

A more concrete impression of the nature of these relationships may be achieved by examining Figures 3 and 4, which illustrate graphically a few of the P-E fit curves. As previously indicated in Table III, associations between the Student Role A-D dimension and School Avoidance (Figure 3, top) are approximately U-shaped for both males and females. While acts of avoidance are most frequent among students reporting large negative discrepancies between student role abilities and demands, they are also relatively high for students reporting excess abilities for this role. In contrast, the association between Student Role A-D and Class Misbehavior is linear and negative for boys, and essentially asymptotic for girls (Figure 3, bottom). Such misbehavior is most frequent among students of either sex whose abilities fall short of the academic or institutional demands of this role, thereafter declining with improved fit throughout the range for males, while leveling off near perfect fit for females.

In Figure 4, significant relationships between the School Relevance and Teacher Support fit indices and three school crime items are plotted to illustrate a strikingly similar pattern of U-shaped relationships. That is, tendencies to destroy school property and threaten or fight with other students are high for boys who want either much more opportunity than they have for relevant schooling, or less opportunity. Similarly, frequencies of committing these acts are low where needs and opportunities for support from teachers match, and increase for boys who want either more or less opportunity for such support than they have.

\section{CONCLUSION}

Overall, these data provide consistent, albeit modest, support for a person-environment fit theory of school crime and disruption. Several significant relationships were found between both ability-demand and opportunityneed dimensions of student-school fit and our three indices of school misbehavior; and several of these relationships manifested one of the nonlinear forms specified by the model. Thus, while both the model and the measures designed 

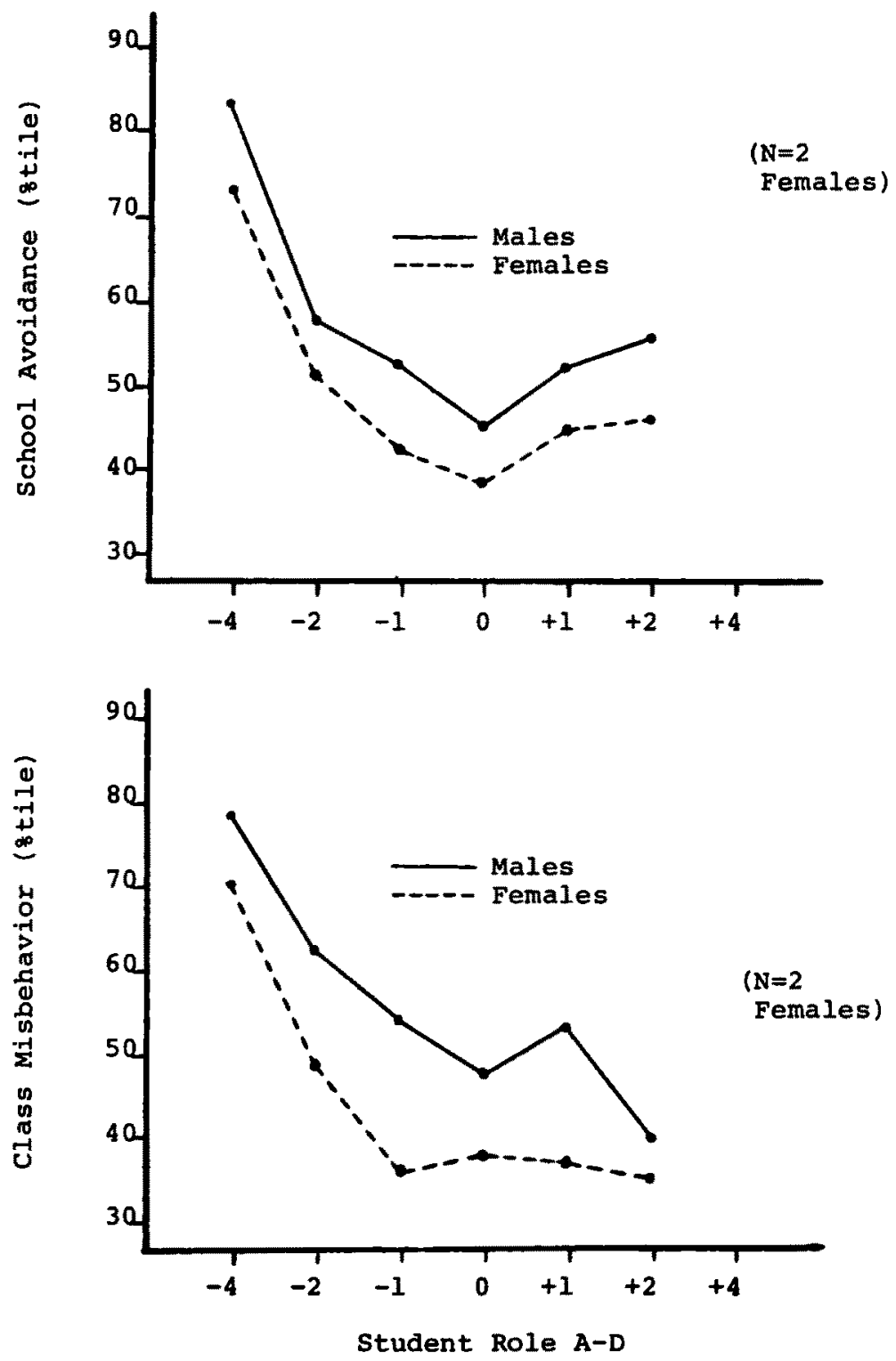

Fig. 3. Student Role ability-demand fit: relationships with School Avoidance and Class Misbehavior. 


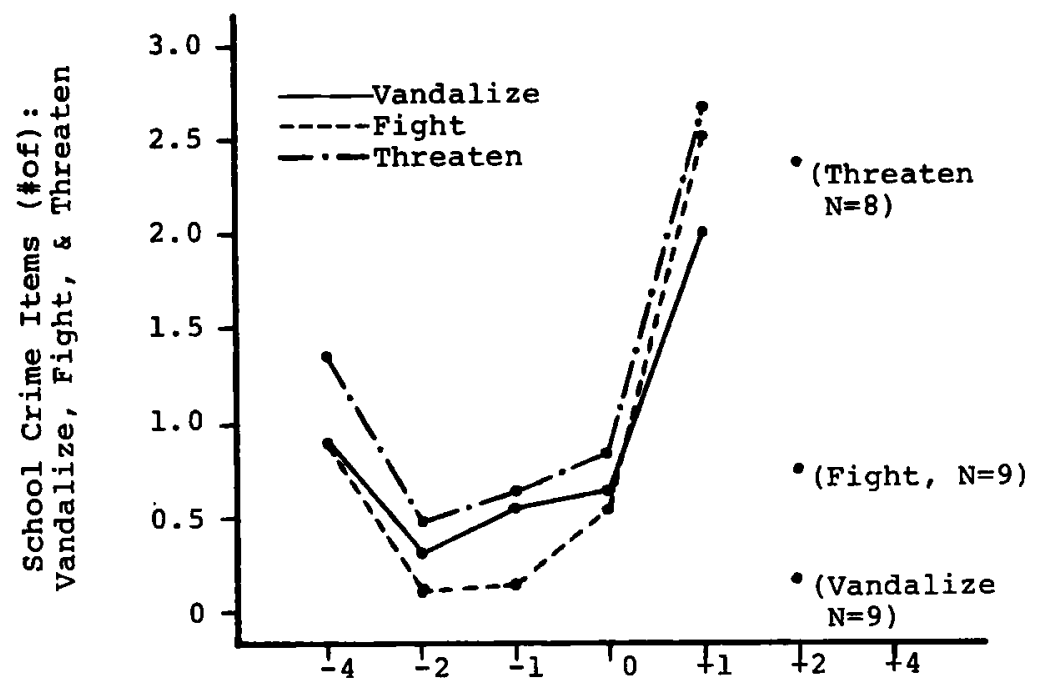

a) School Relevance $\mathrm{O}-\mathrm{N}$

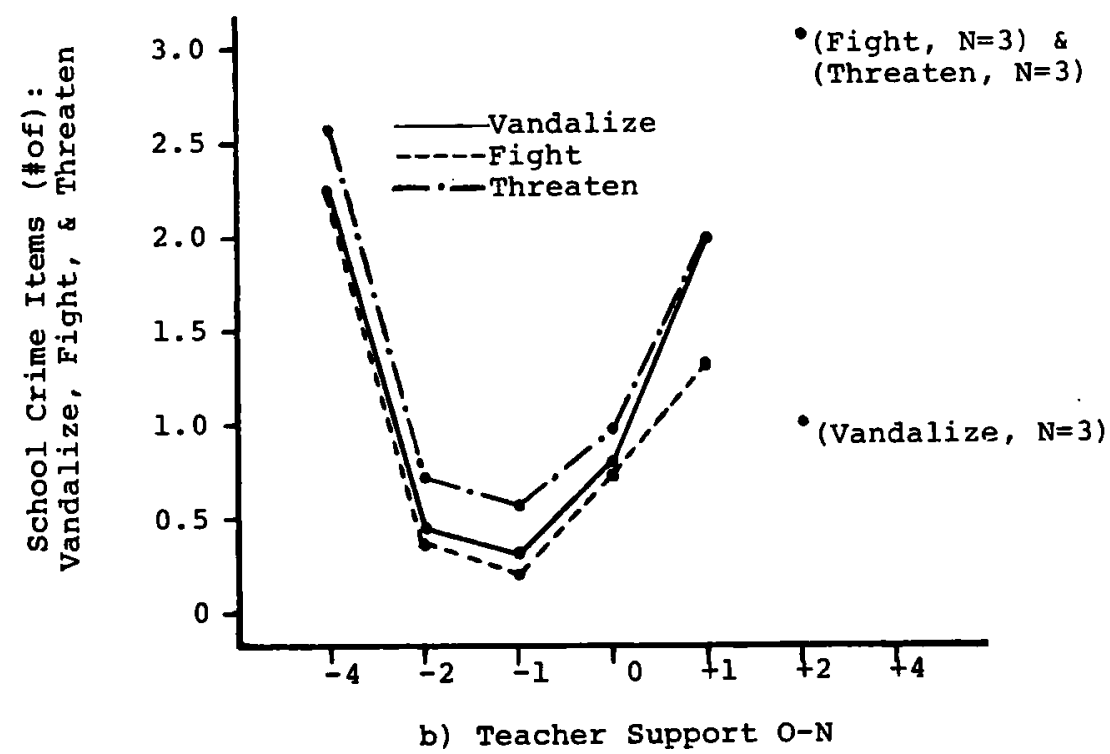

Fig. 4. School Relevance and Teacher Support opportunity-need fit: Relationships with three School Crime items: Vandalize, Fight, and Threaten another student (for males). 
to assess person-environment fit will undoubtedly undergo refinement and elaboration in the future, research strategies based on this conceptualization appear to have considerable potential for improving our understanding of rebellious, disruptive, and delinquent behavior, both within and outside the school context.

\section{REFERENCES}

Bailey, S. K. (1970). Disruption in Urban Public Secondary Schools, National Association of Secondary School Principals, Washington, D.C.

Blalock, H. M., Jr. (1960). Social Statistics, McGraw-Hill, New York.

Caplan, R. D., Cobb, S., French, J. R. P., Jr., Harrison, R. V., and Pinneau, S. R., Jr. (1975). Job Demands and Worker Health: Main Effects and Occupational Differences (USGPO Catalog No. HE 20.7111:J57. USGPO Stock No. 1733-00083), U.S. Government Printing Office, Washington, D.C.

Cardinell, C. F. (1969). Relationship of interaction of selected personality characteristics of school principal and custodian with sociological variables to school vandalism. Unpublished doctoral dissertation, Michigan State University.

Coleman, J. S. (1961). The Adolescent Society, The Free Press, Glencoe, Ill.

Elliott, D. S., and Voss, H. L. (1974). Delinquency and Dropout, D. C. Heath, Lexington, Mass.

Erickson, M. L., Scott, M. L., and Empey, L. T. (1964). School Experience and Delinquency, Brigham Young University, Provo, Utah.

French, J. R. P., Jr. (1973). Person role fit. Occup. Ment. Hlth 3: 15-20.

French, J. R. P., Jr. Rodgers, W., and Cobb, S. (1974). Adjustment as person-environment fit. In Coelho, G. V., Hamburg, D. A., and Adams, J. E. (eds.), Coping and Adaptation, Basic Books, New York.

Glaser, D. (1975). Strategic Criminal Justice Planning. U.S. Government Printing Office, Washington, D.C.

Gold, M. (1978). Scholastic experiences, self-esteem, and delinquent behavior: A theory for alternative schools. Crime Delinq. 24: 290-308.

Goldman, N. (1961). A socio-psychological study of school vandalism. Crime Delinq. 7:221-230.

Greenberg, B. (1975). Program for the Prevention and Control of School Vandalism and Related Burglaries, Stanford Research Institute, Menlo Park, Calif.

Harrison, R. V. (1978). Person-environment fit and job stress. In Cooper, C. L., and Payne, R. (eds.), Stress at Work, Wiley, New York.

Hirschi, T. (1977). Causes and prevention of juvenile delinquency. Sociol. Inquiry 47: 322-341.

Jorgenson, G. W. (1977). Relationship of classroom behavior to the accuracy of the match between material difficulty and student ability.J. Educ. Psychol. 69: 24-32.

Kahle, L. R., Kulka, R. A., and Klingel, D. M. (in press). Low adolescent self-esteem leads to multiple interpersonal problems: A test of social adaptation theory. J. Personal. Soc. Psychol. in press.

Kelly, J. G. (1979). Adolescent Boys in High School: A Psychological Study of Coping and Adaptation, Lawrence Erlbaum, Somerset, N.J.

Kulka, R. A. (1975). Person-environment fit in the high school: A validation study (2 vols.). Doctoral dissertation, University of Michigan (University Microfilms No. 76-9438).

Kulka, R. A. (1979). Interaction as person-environment fit. In Kahle, L. R. (ed.), New Directions for Methodology of Behavioral Science: Methods for Studying PersonSituation Interactions (No. 2), Jossey-Bass, San Francisco.

Kulka, R. A., Klingel, D. M., and Kahle, L. R. (1979). Antecedents and consequences of alienation and involvement in high school. Paper presented at the meeting of the American Psy chological Association, New York, September. 
Kulka, R. A., Mann, D. W., and Klingel, D. M. (in press). A person-nvironment fit model of school crime and disruption. In Rubel, R. J., and Baker, K. (eds.), Theoretical Perspectives on Crime and Violence in the Public Schools, Lexington Books, Lexington, Mass.

Lewin, K. (1951). Field Theory in Social Sciences (Cartwright, D., ed.), Harper \& Row, New York.

Locksley, A., and Douvan, E. (1979). Problem behavior in adolescents. In Gomberg, E. S., and Franks, V. (eds.), Gender and Disordered Behavior: Sex Differences in Psychopathology, Brunner/Mazel, New York.

McPartland, J. M., and McDill, E. L. (1977). Research on crime in schools. In McPartland, J. M., and McDill, E. L. (eds.), Violence in Schools: Perspectives, Programs, and Positions, D. C. Heath, Lexington, Mass.

National Institute of Education, U.S. Department of Health, Education and Welfare (1977). Violent Schools - Safe Schools: The Safe School Study Report to the Congress, Vol. 1, U.S. Government Printing Office, Washington, D.C.

Newman, B. M. (1975). Characteristics of interpersonal behavior among adolescent boys. J. Youth Adoles. 4: 145-153.

Polk, K., and Schafer, W. E. (eds.) (1972). Schools and Delinquency, Prentice-Hall, Englewood Cliffs, N.J.

Strauss, G. H. (1974). Two perspectives on high school student politics: Political objects versus political actors. Youth Soc. 5: 360-376.

U.S. Senate Subcommittee to Investigate Juvenile Delinquency, Committee on the Judiciary (1977). Challenge for the Third Century: Education in a Safe Environment Final Report on the Nature and Prevention of School Violence and Vandalism, U.S. Government Printing Office, Washington, D.C.

Wenk, E. A. (1974). Schools and delinquency prevention. Crime Delinq. Lit. 6: 236-258. West, W. G. (1975). Adolescent deviance and the school. Interchange 6: 49-55.

Wilson, J. Q. (1977). Crime in society and schools. In McPartland, J. M., and McDill, E. L. (eds.), Violence in Schools: Perspectives, Programs, and Positions, D. C. Heath, Lexington, Mass.

Yinger, J. M. (1965). Toward a Field Theory of Behavior, McGraw-Hill, New York. 